\title{
1 Genetic links between endometriosis and cancers in
}

2 women

4 Salma Begum Bhyan ${ }^{1}$, Li Zhao ${ }^{2}$, Yong Kiat Wee ${ }^{1}$, Yining $\mathrm{Liu}^{3}$, Min Zhao ${ }^{1}$

6

$7 \quad{ }^{1}$ School of Science and Engineering, University of the Sunshine Coast, Queensland, 4558,

8 Australia.

$9{ }^{2}$ Dongguan Women and Children's Hospital, 99 Zhenxing Street, Dongguan, 523070, China.

$10{ }^{3}$ The School of Public Health, Institute for Chemical Carcinogenesis, Guangzhou Medical

11 University, 195 Dongfengxi Road, Guangzhou, 510182, China.

12

13 Corresponding Authors:

14 Min Zhao

15 School of Science and Engineering, University of the Sunshine Coast, Queensland, 4558,

16 Australia

17 Email address: $\underline{\text { mzhao@ } @ \text { usc.edu.au }}$

19 Salma Begum Bhyan

20 School of Science and Engineering, University of the Sunshine Coast, Queensland, 4558,

21 Australia

22 Email address: salma.bhyan@ research.usc.edu.au

23 
Endometriosis is a chronic disease occurring during the reproductive stage of women. Although there is only limited association between endometriosis and gynecological cancers with regard to clinical features, the molecular basis of the relationship between these diseases is unexplored. We conducted a systematic study by integrating literature-based evidence, gene expression and large-scale cancer genomics data in order to reveal any genetic relationships between endometriosis and cancers in women. We curated 984 endometriosisrelated genes from 3270 PubMed articles and then conducted a meta-analysis of the two public gene expression profiles related to endometriosis which identified Differential Expression of Genes (DEGs). Following an overlapping analysis, we identified 39 key endometriosis-related genes common in both literature and DEG analysis. Finally, the functional analysis confirmed that all the 39 genes were associated with the vital processes of tumour formation and cancer progression and that two genes ( $P G R$ and ESR 1 ) were common to four cancers of women. From network analysis, we identified a novel linker gene, C3ARI, which had not been implicated previously in endometriosis. The shared genetic mechanisms of endometriosis and cancers in women identified in this study provided possible new avenues of multiple disease management and treatments through early diagnosis.

\section{Introduction}

Endometriosis is a chronic disease of women occurring at the reproductive stage of their lives. Worldwide, approximately 176 million (6-10\%) women are affected by this disease (Kvaskoff et al., 2017) diagnosed by the formation of endometrial-like tissues and lesions, not only on the walls of the uterus but also in the fallopian tubes and on the pelvic wall. It is a common disease that can cause pelvic inflammation, chronic pain and infertility (Giudice and Kao, 2004). The first report on endometriosis-associated ovarian cancer was published in 1927 (Sampson, 1927) and the histological transformation of endometriosis to endometrioid ovarian cancers (EnOC) was reported in 1996 (de la Cuesta et al., 1996). This process has been confirmed by subsequent epidemiological studies (Heidemann et al., 2014, Kim et al., 2014, Kvaskoff et al., 2015). The occurrence of synchronous endometriosis in ovarian cancer lesions was reported by Jimbo et al. (1997) with 23.1 and $43 \%$ of EnOC. A separate epidemiological study showed a 2-3\% higher risk in ovarian cancer patients with endometriosis than controls (Wei et al., 2011). A significant positive association was observed with different histological subtypes of ovarian cancers, particularly with endometroid, epithelial and clear cell types (Saavalainen et al., 2018, Gandini et al., 2019, Pearce et al., 2012). Pearce et al. (2012) reported that endometriosis is associated with an increased risk of clear cell type ovarian cancer. The highest rate of incidence ratio of ovarian cancer was observed among women with ovarian endometriosis, particularly endometrioid and clear cell types (Saavalainen et al., 2018). In addition, endometriosis has been found to show more modest association with seromucinous borderline (Maeda and Shih, 2013, Samartzis et al., 2013) and low-grade serous ovarian carcinomas (Pearce et al., 2012). Sequencing and immune-histochemical studies have demonstrated a clonal relationship 
between benign and malignant counterparts suggesting that the cancers may have arisen from the endometriotic lesions (Anglesio et al., 2015, Chene et al., 2015, Stamp et al., 2016, Wiegand et al., 2010).

Endometriosis, along with breast cancer, are estrogen-dependent chronic gynecological disorders and have similar risk factors associated with reproduction and the use of hormone replacement therapy (Munksgaard and Blaakaer, 2011). In addition, both endometriosis and cancer exhibit uncontrolled, estrogen-dependent proliferation, invasion, neo-angiogenesis and metastases (Burney and Giudice, 2012, Thomas and Campbell, 2000). Previous studies have identified the connection between endometriosis and breast cancer (BC) (Kokcu, 2011, Kvaskoff et al., 2015). In Denmark, data collected from 1977 to 2012 on 114,327 women showed that women who were diagnosed as endometriosis positive before age 40 had a $14 \%$ reduced risk of breast cancer than those diagnosed between age 40 and 50 . Women diagnosed at age 50 or older were more than twice as likely to develop breast cancer as women of the same age who did not have endometriosis (Mogensen et al., 2016). Bulletti et al. (2010) reported that 20-25\% of patients might be asymptomatic during the diagnosis of endometriosis. Although it is plausible that endometriosis is associated with increased risks for endometrial and breast cancer, epidemiological studies of the association are inconsistent.

Cervical cancer is the abnormal growth of cells in the lining of the cervix. The most common cervical cancer is squamous cell carcinoma (Marwah et al., 2012). On the other hand, cervical endometriosis is rare and often shows no symptoms. An epidemiological study of the association between the two diseases has reported the decreased risk of cervical cancer (Kvaskoff et al., 2015). A recent study suggested an association between cervical clear cell carcinoma (CCC) and cervical endometriosis (Hashiguchi et al., 2018). However, a decreased risk of cervical cancer of squamous cell histology among women with endometriosis has been suggested (Saavalainen et al., 2018).

Although endometriosis and endometrial cancer are two separate diseases, epidemiological, biological, and molecular data suggest that there could be links between the two disorders (Kvaskoff et al., 2015). Endometriosis is characterized by the formation of endometrial-resembling tissue external to the uterus while endometrial cancer (sometimes called uterine cancer) begins in the layer of cells that form the lining (endometrium) of the uterus. Endometriosis and endometrial cancer are both hormonally regulated diseases, having a common risk factor (higher levels of estrogen) and similar treatment measures (contraceptive pill and hormonal therapies) (Wetendorf and DeMayo, 2012). Both are involved in increased risk of uterine fibroids (Rowlands et al., 2011, Uimari et al., 2011). The predominant symptom of endometrial cancer is pelvic pain, which is also one of the main symptoms of endometriosis. In a recent genetic study, it was identified that these two diseases have common genetic causes (Painter et al., 2018). However, some previous studies showed the opposite or no significant association. Kvaskoff (2015) reported eight studies on the association between endometriosis and endometrial cancer and that there was no association in five studies where numbers of endometrial cancer cases ranging from 12 to 97 (Brinton et al., 1997, Brinton et al., 2005, Melin et al., 2007, Venn et al., 1999). Two studies 
107 showed an association between endometriosis and increased endometrial cancer risk (Melin

108 et al., 2006, Zucchetto et al., 2009) but one study suggested a significant inverse association

109 (Borgfeldt and Andolf, 2004).

110 Therefore, a detailed investigation on the genetic control of the different cancer types 111 along with endometriosis is necessary in order to explore the relationships between these two 112 diseases. Over the last few decades, a large number of genetic data have been generated using 113 next generation sequencing (NGS) technology and these can be used to decipher the genetic

114 relationships between the two types of diseases. Therefore, we have conducted a meta-

115 analysis of NGS data to explore evidence concerning the genomic and functional

116 relationships of endometriosis and cancers in women.

\section{Materials and Methods}

\section{Endometriosis-related gene curation from the literature}

To explore the genetics of endometriosis, we conducted a literature search and extracted 3270 records from the GeneRIF (Gene Reference into Function), a database providing lists of genes and their functions (Maglott et al., 2010). We curated the literature data manually to extract the corresponding gene names. In total, we curated 984 genes related to studies of endometriosis and used these as a basis to explore similarities in the genetic mechanisms of cancers.

\section{Differential gene expression for endometriosis dataset}

To obtain independent evidence at the expression level, we focused on those studies which compared endometriosis patients with healthy individuals We downloaded two datasets (GSE2339 and GSE5108) related to endometriosis that were collected from the gene expression omnibus (GEO) database, a repository of high-throughput gene expression data of original submitter-supplied records and curated records. Using GEO2R, we compared endometriosis samples with that of healthy individuals and, using the data filtering criteria of adjusted $P$ values $<0.05$ and an absolute fold change $>2$, identified genes that are differentially expressed (Barrett et al., 2012). Overlapping analysis was conducted to identify genes common to the two GEO datasets and the curated endometriosis gene lists.

\section{Mutational Analysis}

The cancer related mutational analyses were conducted using the cBio portal (Cerami et al., 2012) which enables the exploration, visualization and analysis of multidimensional cancer genomics data. We selected the TCGA datasets (Tomczak et al., 2015) of cancers in women including ovarian serous cystadenocarcinoma, cervical squamous cell carcinoma, breast invasive carcinoma, and endometrial carcinoma in order to analyse the mutational frequency of the genes that are related to endometriosis. The combined studies dataset contained a total of 7462 samples. 


\section{Functional Enrichment and Network analysis}

To investigate the biological systems in the endometriosis-related genes, we analysed the genes common to endometriosis and the differential expression of endometriosis by using the online tools Toppfun (Chen et al., 2009), REVIGO (Supek et al., 2011) and GeneMania (Warde-Farley et al., 2010). The molecular functions of the key endometriosis-related genes were analysed using ToppFun. ToppFun is a web tool which allows users to explore the molecular functions of gene ontology (GO) including cellular components, biological processes and molecular functions. We extracted gene IDs and their corresponding $\mathrm{P}$ values for the visualization process using REVIGO. REVIGO summarized and removed the redundant GO terms from a long list. The GO results served as input data in REVIGO and provided a semantic similarity-based scatterplot of GO terms from Toppfun. To perform the network analysis we used GeneMania to identify the interactions of the selected genes and Cytoscape (Shannon et al., 2003) to characterize and visualise the network results.

\section{Results}

\section{Identification of potential endometriosis-related genes}

In order to explore the association between endometriosis and four cancers of women, we identified the genes commonly implicated in those diseases (Figure 1). To achieve this, we manually curated endometriosis-related genes from 3273 PubMed abstracts (Table S1). The curated results were mapped based on their official gene names in concordance with data integration for other cancer genomics data sources. In total, we curated 984 endometriosis genes. To further refine the key genetic factors related to the endometriosis, we performed differential expression analyses on two endometriosis-related expression datasets: GSE2339 and GSE5108. GSE2339 is a two disease (endometrioma and eutopic endometrium ) state set presenting the molecular mechanisms underlying the pathology of endometriosis (Hawkins et al., 2011). GSE5108 presents the gene expression profile of endometriosis (Eyster et al., 2007).

Using a cut-off as the adjusted $\mathrm{P}$ value $<0.05$ and the absolute fold change $>2$, we identified 1037 genes associated with endometriosis (Table S2) from GSE2339 and 800 from the GSE5108 datasets. The overlapping results revealed that $165(39+65+61)$ genes (Figure 1A) shared at least one GEO dataset and curated gene list and, of these, 65 and 61 genes are common to GSE2339 and GSE5108, and 39 are in both GEO datasets. Using these lists, we explored the key molecular processes for the endometriosis. In summary, our computational workflow integrated the literature curated endometriosis genes with two other GEO endometriosis datasets.

\section{Functional analysis of major endometriosis-related genes common in GEO datasets and curated list}

Functional enrichment analysis of the 165 genes shared by our curated endometriosisrelated gene list and at least one GEO dataset was conducted using Gene Ontology (GO) 
181 terms as functional units (Figure 1C). The results revealed the genes enriched with cell proliferation (GO: 0042127; p-value: 1.03E-41), growth (GO: 0040007; p-value: 2.17E-21), apoptotic process (GO: 0006915; p-value: 5.54E-21), and cell adhesion (GO: 0007155; pvalue: 1.47E-17) (Table S3). All these gene functions are associated with cancer progression. In addition, we identified hormone stimulating genes involved in the occurrence of endometriosis. Eighteen genes were found to be involved in the responses to estrogen $(\mathrm{P}-$ value $=2.45 \mathrm{E}-12)$, five $(P T G E R 4, P T N, T H B S 1, C C L 2, C 3)$ to progesterone $(\mathrm{P}$-value=7.45E$05)$ and 45 to cytokine $(\mathrm{P}-\mathrm{value}=9.567 \mathrm{E}-24)$. Thirty-one genes were associated with cytokine production (P-value=7.03E-14) and 17 genes involved in the ERK1 and ERK2 cascades (Pvalue $=5.27 \mathrm{E}-10)$ (Table S3). In addition, biological adhesion (GO: 0022610; P-value= 2.04E17 ) and $M A P K$ cascade (GO: 0000165; P-value $=2.00 \mathrm{E}-17$ ) play important roles in cell development processes related to cancer progression.

We conducted another functional enrichment analysis using ToppFun to explore the functions of the 39 genes common to both GEO data sets and the curated endometriosis gene list (Figure 1B). This showed that the genes are enriched in most of the vital processes in cancer and tumor progression including: apoptotic process (GO: 0006915; P-value=3.47E06), the regulation of the cell cycle (GO: 0051726; $\mathrm{P}$-value $=4.48 \mathrm{E})$, cell proliferation (GO: 0042127; P-value= 1.26E-11), cell death (GO: 0010941; P-value=4.95E-07), and cell differentiation (GO: 0045595; P-value=1.06E-07). Our study also found that five genes are also involved in the enrichment of estrogen (GO: 0043627; P-value $=1.22 \mathrm{E}-04)$ and four in the enrichment of progesterone (GO: 0032570; P-value=3.53E-06). Ten genes were found to be associated with angiogenesis (GO: 0001525; P-value=2.79E-08), twelve genes in responses to cytokine (GO: 0034097; P-value= 6.83E-08) and seven genes in cytokine production (GO: 0001816; P-value= 5.54E-04). Eleven genes were involved in the MAPK pathway (GO: 0000165; P-value=2.05E-06) and five genes were involved in ERK1 and ERK2 cascade (GO: 00703; P-value=3.00E-04) (Table S4).

As presented in supplementary Table $\mathrm{S} 3$ and $\mathrm{S} 4$, our study identified that $C 3$ is common in both estrogen, progesterone, angiogenesis, cytokine production, MAPK pathway, $E R K 1$, and ERK2. Pleiotrophin (PTN)), a member of a highly conserved human gene family (Rauvala, 1989), is common in the apoptotic process, cell cycle, cell proliferation, cell death, cell differentiation, progesterone, estrogen, and angiogenesis. LEP is common in the apoptotic process, cell cycle, cell proliferation, cell death, cell differentiation, estrogen, angiogenesis, cytokine, cytokine production, and MAPK pathway. Both CCL2 and THBSI are involved in the apoptotic process, cell proliferation, cell death, progesterone, angiogenesis, cytokine production, and MAPK pathway. AGTRl is involved in the apoptotic process, cell proliferation, cell death, cell differentiation, estrogen, and cytokine production. ESRl is involved in cell cycle, cell proliferation, cell death, estrogen, and the MAPK ERK1 and ERK2 pathways. PLCB1 and CSF1R are concerned in the cytokine and MAPK pathways. GATA2, SOX17, DCN, PTGIS, and NRP2 are involved in angiogenesis; AIF1, CXCL16, IRF6, MME, FOXA2, DCN, PTGIS, TNFSF13B in cytokine; and NGF, PLA2G2A, LPAR3, and NTF3 in the MAPK pathway only. 


\section{Interconnectivity of Endometriosis-related genes}

In order to identify the interconnectivity of endometriosis-related genes, we conducted a network analysis of the 165 genes which shared at least one GEO dataset (Figure S1) and the curated gene list of endometriosis. We performed network analysis, using GeneMania and Cytoscape, and identified correlations among the genes of interest. To avoid the potential of a large number of non-significant correlations, we used only reliable interactions (Cerami et al., 2010). Additionally, we compared the results from the 165 genes with another network analysis focusing on 39 common genes of curated endometriosis genes and both GEO data sets.

The network analysis of the 165 endometriosis related genes showed that most of the genes has more than 20 connections. We found maximum connections (75) in SPARC followed by FN1 (72), VCAMI (61), DAPK1 (54), CD14 (53), HLA-DRA (53), TFAP2C (51), CCR1 (50), CDH3 (47), CXCL12 (46), TIMPI (46), BGN (45), CSF1R (43), MMP9 (43), CNN1 (41), LIPC (41), CDHI (40). From the derived network, we identified novel linker genes showing functional links with the endomitriosis related genes. Among the identified linker genes, twenty genes (CXCL9, TNFAIP6, FAP, A2M, TIMP3, CCL18, FCER1G, MMP2, CD68, C1QB, TNC, FPR1, CCL5, C3AR1, IGF1, ACTA2, TYROBP, MMP1, AOAH and $C O L 3 A 1$ ) have more than $>20$ connections. Results suggested that these linker genes can be used in prognostic studies of endometriosis.

A network analysis of 39 genes is presented in (Figure 2A). By focusing on genes with the highest number of interactions, we found eight genes with 10 or more connections. Gene TAGLN had highest number of connections (23) followed by CSF1R (17), ESR1 (16), THBS1 (16), IRF6 (14), PLA2G2A (12), BDNF (10), and PLCB1 (10). We also revealed 20 novel linker genes (VEGFA, NTF4, PAX2, PAX5, CD47, CF1, CSF1, C3AR1, IGFBP1, PGF, FOXF1, OVGP1, IRF8, IRF5, MDK, PARD6A, PARD3, TNFRSF13C, FEZ1, and IGFBP5) connected with the 39 genes. Among the linker genes, 16 genes had 10 or more connections with highest in CFI (25) followed by C3ARI (24), IGFBPI (21), VEGFA (19), IRF8 (18), IGFBP5 (18), CSF1 (15), PARD3 (15), FEZ1 (14), FOXF1 (14), OVGP1 (13), PARD6A (13), CD47 (12), PGF (12), IRF5 (10), and PAX2 (10).

The network topological analysis identified 59 gene nodes and 364 gene-gene interactions, which showed that the majority of the gene nodes have multiple connections (Figure 2B). Of the 59 nodes, 39 were identified from our gene list and the remaining 20 were linker genes. The degrees of the nodes in the map fit a power law distribution $y=a x^{b}$, where $a=2.684$ and $\mathrm{b}$ is an exponent with an estimated value of -0.110 . The correlation between the given data point and the corresponding point on the fitted curve is $0.195\left(\mathrm{R}^{2}=\right.$ 0.014). Topological analysis on the shortest path length distribution analysis shows that the average length of the shortest path is 2 , which indicates that the number of nodes which instantly connected (Figure 2C). 

data sets

We conducted a mutational analysis of the 39 listed genes of endometriosis using TCGA datasets associated with four cancers of women. For mutational analysis, we used 7462 TCGA samples collected from 11 studies, consisting of 3834 breast, 1754 ovarian, 1577 endometrial and 297 cervical cancers. The frequency of alteration in cBio Cancer Genomics Portal is defined by mutation, copy number amplification, and homozygous deletion in tumor samples (Cerami et al., 2012). Alteration frequency of the TCGA samples revealed that all the 39 genes have a high alteration rate in the tumor samples as revealed by gene amplifications. For example, of the 585 cases of TCGA ovarian epithelial tumor, the frequency of genetic alterations was $60.17 \%$ of which the highest alteration was observed in amplification (37.44\%, 219 cases) followed by deep deletion (10.6\%, 62 cases) (Figure 3C). In 1169 cases of ovarian cancer, we observed $54.06 \%$ alteration and $41.75 \%$ of these were due to amplification. For endometrial carcinoma, the frequency was tested in 529 cases and $59.74 \%$ showed genetic alteration with maximum of these being in mutation (34.85\%). For invasive breast carcinoma TCGA cohort (of 1086 cases), $40.88 \%$ of all were genetically altered and $21.73 \%$ of these were due to amplification. The cervical squamous cell carcinoma had $41.83 \%$ genetic alteration from 251 cases with highest number due to amplification (17.93\%) (Figure 3E). These results showed the importance of endometriosis-related genes in the development of cancers in women as a consequence of their function in promoting a large number of copy number gains (Wee et al., 2018).

In addition to the sample analysis, we explored the genomic alterations in multiple genes across several tumor samples (Figure 3A-D). We used the OncoPrint in cBioportal for a query search of alterations in the 39 endometriosis-related genes in TCGA ovarian serous cystadenocarcinoma, TCGA breast invasive carcinoma, TCGA uterine corpus endometrial carcinoma, and TCGA cervical squamous cell carcinoma tumor samples. An oncoprint is a graphical display of gene mutations in human cancer tumor samples. We further identified the top 10 genes with the highest amplification rate in samples of four cancer types. (Figure 3A-D). For ovarian serous cystadenocarcinoma, there was a total of 12 (MME, AGTRl, SOX17, PTN, NTF3, MSR1, PGR, PLCB1, BNC2, PTGIS, LEP, and PAX8) genes with >4\% of genetic alterations frequency. IRF6 showed 6\% and SOX17, MSRI, PTGIS showed 3\% in the TCGA breast invasive carcinoma tumor samples. In TCGA uterine corpus endometrial carcinoma samples, there were nine (SOX17, C3, PAX8, ESR1, MME, MSRI, BNC2, IRF6, and $P G R$ ) genes with $>5 \%$ alteration frequency. Three genes (MME, $P G R$, and AGTRI) showed $>7 \%$ alteration frequency in the TCGA cervical squamous cell carcinoma. Most of these alterations were related to amplification. MME, SOX17, AGTR1, PGR, and ESRI had the highest amplifications frequency ranging from $4 \%$ to $11 \%$ in ovarian serous cystadenocarcinoma. We observed similar features in the uterine corpus endometrial carcinoma dataset: the genes with the highest frequency included SOX17 and $C 3$ (8\%), PAX8, $M M E$ and $E S R 1$ (7\%). In breast invasive carcinoma, IRF6 showed the highest rate of alteration (6\%) followed by SOXI7 and MSRI (3\%). In the case of cervical squamous cell carcinoma, alteration frequency was greatest in $M M E(10 \%)$, followed by $P G R(9 \%)$ and 
AGTRI (8\%). Therefore, all these endometriosis-related genes are associated with gene amplification events across the four cancers of women TCGA samples.

\section{Mutational analysis of linker genes involved in the endometriosis network}

We applied the network analysis and constructed a gene network to identify the global connections of the 39 genes identified by overlapping analysis between endometriosis-related genes and two GEO datasets. The derived network comprised 20 linker genes that were shown to connect with core genes. Interestingly, one of those linker genes $(C 3 A R l)$ is within the 165 full gene list, which was identified by overlapping analysis between literature-based endometriosis-related genes and one set of GEO datasets.

The additional mutational analysis on the 20 linker genes, including C3ARI (Figure $4 \mathrm{~A})$, showed a significant amplification frequency across tumor samples. Eighty percent of the genes showed more than $1 \%$ genetic alterations in eleven TCGA datasets from four cancer types: breast invasive carcinoma, cervical squamous cell carcinoma, ovarian serous cystadenocarcinoma, and uterine corpus endometrial carcinoma. The TCGA ovarian serous cystadenocarcinoma patients had $>40 \%$ genetic alteration/expression (median) (Figure 4B). Overall, most of cancer cohort patients showed $>20 \%$ genetic alterations. Based on 7462 samples, the greatest rate of alteration was observed in PARD3 and C3ARI (both 3\%), followed by $C D 47$ (2.6\%) and IRF8 (2.4\%). The graphical presentation of expression result from cBioportal (Figure 4B) revealed that the maximum expression of C3ARI was found in breast cancer samples followed by ovarian then cervical cancers and minimum in uterine or endometrial cancers.

\section{Mutational and functional analysis of common genes involved in endometriosis and cancers in women}

Overlapping analysis of 165 endometriosis genes and previously identified 52 genes of four women cancers (Bhyan et al., 2019) revealed that nine genes were common: SPARC, CDH1, MET, TIMP1, BRCA1, IGF2, PGR, MMP9 and ESR1 (Figure S2). PGR and ESR1 are also found in the list of the common 39 genes from the three endometriosis-related data sets. Further analysis revealed that all the nine genes are frequently mutated and the frequency varied from $1 \%$ to $8 \%$ (Figure $5 \mathrm{~A}$ ). Gene $\mathrm{CDH} 1 \mathrm{l}$ had the highest rates of alteration (8\%) followed by BRCAI (4\%), PGR (4\%) and ESRI (4\%). IGF2 had the lowest rate of alteration $(1 \%)$. TCGA data sets collected from the eleven studies provided 7462 samples in which the maximum rate of genetic alteration occurred in endometrial carcinoma (36.86\% of 529 cases), followed by ovarian epithelial tumor (27.69\% of 585 cases), invasive breast carcinoma (26.7\% of 1086 cases), and ovarian cancer (26.26\% of 1169 cases) (Figure 5B).

Functional enrichment analysis revealed that the nine genes were associated with a number of key cancer pathways and reproductive system biological processes including: the progesterone receptor signalling pathway (GO: 0050847; P-value $=2.90 \mathrm{E}-03$ ); the hormonemediated signalling pathway (GO: 0009755; P-value=1.46E-04); and the intracellular receptor signalling pathway (GO: 0030522; P-value=3.20E-04) (Table S3). Among the nine 
genes, $P G R$ and $E S R I$ were involved in all three pathways and $P G R$ alone was involved in

344 the progesterone receptor signalling pathway. These results suggested that endometriosis and four women cancers arise from common genetic mutations.

\section{Discussion}

Endometriosis is the hormone-dependent abnormal growth of endometrial epithelial and stromal cells outside the uterine cavity which may cause chronic pelvic pain, subfertility and result in an increased risk of ovarian cancer (Vercellini et al., 2014, Saavalainen et al., 2018, Pearce et al., 2012). In a previous study, we identified some key driver genes of four cancers of women which function as hormonal stimulants (Bhyan et al., 2019). But, the highgrade serous ovarian cancers data set from TCGA are not strongly associated with endometriosis and the clear cell and endometrioid OCs that are associated with OC are not represented in TCGA. However, Dawson et al. (2018) suggested that endometriosis and four cancers of women may share common biological mechanisms. Previous studies demonstrated that there was an increased risk of ovarian and breast cancer due to endometriosis (Saavalainen et al., 2018, Pearce et al., 2012, Saavalainen et al., 2019). Our research involved a meta-genomic study on endometriosis-related genes and an assessment of their involvement in four women cancers: breast, cervical, ovarian and endometrial. Integrated analyses, including functional enrichment, network, and mutational analysis provided a list of key genes playing dual role in endometriosis and women cancers.

In this study, functional analysis of endometriosis-related genes revealed shared mechanisms of endometriosis concerned with four cancers of women. This was particularly the case for cell proliferation, growth, apoptotic process, cell adhesion, regulation of cell cycle, regulation of cell death, and regulation of cell differentiation. The control of cell proliferation and apoptosis are the key regulatory mechanisms of cancer progression. The apoptotic process is highly regulated in human cells and essential for maintaining the physiological balance between cell death and cell growth (Koff et al., 2015). Different extracellular and intracellular signals, including hormones, growth factors and cytokines, can stimulate the different pathways (Dhillon et al., 2007) and regulate cell differentiation, growth and apopotosis (Kim and Choi, 2010). We identified common hormone stimulant pathways, including enrichment of estrogen and progesterone, angiogenesis, response to cytokine, and cytokine production, as functional roles of endometriosis-related genes. Estrogen and progesterone are the key hormones involved in reproductive development but are also associated with tumor growth and the spread of some cancers (Subramani et al., 2017). It has been shown that estrogen exposure is directly associated with an increase in the risk of developing breast cancer (Begg et al., 1987, Pike et al., 1979), whereas reducing exposure is thought to be protective against breast cancer (Hulka, 1997). Estrogen also increases the risk of ovarian cancer, particularly after menopause (Ho, 2003). Progesterone and progesterone receptors (PR) are important because of their role as critical regulators of breast and gynecological cancers. Although the uptake of both estrogen and progesterone reduces the risk of ovarian cancer, the mechanisms explaining the role of these two hormones 
ovarian cancer (Gavalas et al., 2013), also has a key functional role in endometriosis. Several studies have indicated that the further outgrowth of ectopic endometrial implants through endometriosis leads to tumor formation (Shubik, 1982). Furthermore, the cancer-modifier cytokines were found to be involved in endometriosis (Brower, 2005) and the cytokinins are both tumor necrosis factors (Esquivel-Velázquez et al., 2015) as well as being associated with a number of gynaecological cancers (Heikkilä et al., 2008, Murooka et al., 2005).

Our study showed that kinase signalling pathways, such as MAPK (mitogen-activated protein kinases), ERK1 and ERK2, are activated in endometriosis. MAPK act as integration points for many biochemical signals and are involved in a variety of cellular processes, including cell proliferation, differentiation, transcription regulation and development (Imajo et al., 2006). In association with several environmental stimuli such as, hormones and cytokines play a role in activating MAPK pathways (Imajo et al., 2006). The dysregulation of protein kinase stimulated by several oncogenic driver mutations was found to accelerate uncontrolled cellular proliferation in kinase-dependent tumour growth (Burotto et al., 2014, Sawyers, 2003). ERK1 and ERK2 are two extracellular regulated kinases and the final effectors of the MAPK pathway (Robinson and Cobb, 1997, Liu et al., 2018). In addition, they are both regulators of malignant breast cancer cells (Milde-Langosch et al., 2005). Therefore, these kinases were identified as potential targets for the treatment of cancers and endometriosis. Endometriosis-related genes identified in this study were found to be associated with key biological mechanisms controlling cancers in women. $C 3$ is a plasma protein which increases cell proliferation once synthesized in malignant ovarian epithelial cells (Cho et al., 2014). PTN is a member of a highly conserved human gene family (Rauvala, 1989) and is a key gene in the process of endometriosis and regulates multiple functions, including apoptosis, cell cycle, cell proliferation, cell differentiation, progesterone and estrogen production, and angiogenesis (Table S4). Overexpression of PTN in breast cancer cells, such as $M C F-7$ gene enhanced angiogenesis in the rabbit corneal assay (Choudhuri et al., 1997). In addition, a truncated form of PTN was shown to act as a dominant-negative effector on the proliferation and angiogenesis of breast cancer cells, in vitro and in vivo (Ducès et al., 2008). Another endometriosis-related gene, LEP, functions as a key mediator in obesity-associated cancers including breast, colorectal and prostrate (Renehan et al., 2010).

From the network analysis of 165 and 39 genes, we identified only one common linker gene, $C 3 A R 1$, although there is no evidence of its involvement with endometriosis. C3ARl is an oncogenic gene that down regulates in tumour cells (Nabizadeh et al., 2016, Yamada et al., 2017). Formerly, $C 3 A R l$ was considered to be involved in the innate immune response but is now regarded as a factor in cancer (Opstal-van Winden et al., 2012). Additionally, C3ARl was found to activate the PI $3 K-A K T$ pathways that result in cell proliferation (Cho et al., 2016, Towner et al., 2016). Further investigation of the involvement of this gene in endometriosis and four cancers of women is important for future disease management.

We identified that the alteration frequency was highest (5\%) in SOX17, which is involved in oncogenesis through tumour suppression, down-regulating MAML3 expression, 
modulating nuclear $\beta$-catenin and antagonizing Wnt signaling (Zhang et al., 2016). Gene $I R F 6$, a transcriptional activator which plays critical roles in endometrial gene expression and the growth and differentiation conceptus trophectoderm (Fleming et al., 2009), also showed $5 \%$ alteration frequency in our study. High rate $(5 \%)$ of mutation frequency was observed in macrophage metalloelastase $(M M E)$, which is a zinc-dependent endoprotease and also involved in ECM re-modulation and conversion of plasminogen to angiostatin (LavillaAlonso et al., 2012). Finally, we discovered eight genes (MME, SOX17, AGTR1, PGR, ESR1, $P A X 8, C 3$ and IRF6) with high amplification frequency compared to other genes across the cancer types. These genes are all involved in endometriosis suggesting their involvement in the progression of cancers in women.

\section{Conclusion}

Using integrated bioinformatic analysis we discovered evidence of genetic link between endometriosis and women cancers. We utilized information from next generation sequence data and compiled a list of a large number of endometriosis related genes. Functional analysis confirmed that 39 genes were associated with the processes of tumour formation and cancer progression of which two ( $P G R$ and ESRI) were common to four cancers of women. Mutational analysis proved that eight endometriosis genes had a higher rate of alterations across the four women cancers. Finally, we explored a novel linker gene, $C 3 A R 1$, which had not been implicated previously in endometriosis. The evidence of shared genetic mechanisms of endometriosis and cancers in women may be an avenue of future disease management and treatment through early diagnosis. This paper provides a catalogue of genetic links between endometriosis and cancer as a guide for further investigation and analysis.

\section{Acknowledgements}

The authors thank to two anonymous reviewers and the academic editor (Kate Lawrenson) of PeerJ for reviewing the manuscript and providing suggestions to improve the manuscript. We thank Professor Richard Burns (University of the Sunshine Coast) and Dr Mobashwer Alam (The University of Queensland) for their assistance in language editing and putting the manuscript in order.

\section{References}

ANGLESIO, M. S., BASHASHATI, A., WANG, Y. K., SENZ, J., HA, G., YANG, W., ANIBA, M. R., PRENTICE, L. M., FARAHANI, H. \& LI CHANG, H. 2015. Multifocal endometriotic lesions associated with cancer are clonal and carry a high mutation burden. The Journal of pathology, 236, 201-209. BARRETT, T., WILHITE, S. E., LEDOUX, P., EVANGELISTA, C., KIM, I. F., TOMASHEVSKY, M., MARSHALL, K. A., PHILLIPPY, K. H., SHERMAN, P. M. \& HOLKO, M. 2012. NCBI GEO: archive for functional genomics data sets-update. Nucleic acids research, 41, D991-D995.

BEGG, L., KULLER, L. H., GUTAI, J. P., CAGGIULA, A. G., WOLMARK, N., WATSON, C. G. \& RAO, D. 1987. Endogenous sex hormone levels and breast cancer risk. Genetic epidemiology, 4, 233247. 
BHYAN, S. B., WEE, Y. K., LIU, Y., CUMMINS, S. \& ZHAO, M. 2019. Integrative analysis of common genes and driver mutations implicated in hormone stimulation for four cancers in women. PeerJ, 7, e6872.

BORGFELDT, C. \& ANDOLF, E. 2004. Cancer risk after hospital discharge diagnosis of benign ovarian cysts and endometriosis. Acta obstetricia et gynecologica Scandinavica, 83, 395-400.

BRINTON, L. A., GRIDLEY, G., PERSSON, I., BARON, J. \& BERGQVIST, A. 1997. Cancer risk after a hospital discharge diagnosis of endometriosis. American journal of obstetrics and gynecology, 176, 572-579.

BRINTON, L. A., WESTHOFF, C. L., SCOCCIA, B., LAMB, E. J., ALTHUIS, M. D., MABIE, J. E. \& MOGHISSI, K. S. 2005. Causes of infertility as predictors of subsequent cancer risk. Epidemiology, 16, 500-507.

BROWER, V. 2005. Researchers Attempting To Define Role of Cytokines in Cancer Risk. JNCI: Journal of the National Cancer Institute, 97, 1175-1177.

BULLETTI, C., COCCIA, M. E., BATTISTONI, S. \& BORINI, A. 2010. Endometriosis and infertility. Journal of assisted reproduction and genetics, 27, 441-447.

BURNEY, R. O. \& GIUDICE, L. C. 2012. Pathogenesis and pathophysiology of endometriosis. Fertility and sterility, 98, 511-519.

BUROTTO, M., CHIOU, V. L., LEE, J. M. \& KOHN, E. C. 2014. The MAPK pathway across different malignancies: a new perspective. Cancer, 120, 3446-3456.

CERAMI, E., GAO, J., DOGRUSOZ, U., GROSS, B. E., SUMER, S. O., AKSOY, B. A., JACOBSEN, A., BYRNE, C. J., HEUER, M. L. \& LARSSON, E. 2012. The cBio cancer genomics portal: an open platform for exploring multidimensional cancer genomics data. AACR.

CERAMI, E. G., GROSS, B. E., DEMIR, E., RODCHENKOV, I., BABUR, Ö., ANWAR, N., SCHULTZ, N., BADER, G. D. \& SANDER, C. 2010. Pathway Commons, a web resource for biological pathway data. Nucleic acids research, 39, D685-D690.

CHEN, J., BARDES, E. E., ARONOW, B. J. \& JEGGA, A. G. 2009. ToppGene Suite for gene list enrichment analysis and candidate gene prioritization. Nucleic acids research, 37, W305W311.

CHENE, G., OUELLET, V., RAHIMI, K., BARRES, V., PROVENCHER, D. \& MES-MASSON, A. M. 2015. The ARID1A pathway in ovarian clear cell and endometrioid carcinoma, contiguous endometriosis, and benign endometriosis. International Journal of Gynecology \& Obstetrics, 130, 27-30.

CHO, M. S., RUPAIMOOLE, R., CHOI, H.-J., NOH, K., CHEN, J., HU, Q., SOOD, A. K. \& AFSHARKHARGHAN, V. 2016. Complement component 3 is regulated by TWIST1 and mediates epithelial-mesenchymal transition. The Journal of Immunology, 196, 1412-1418.

CHO, M. S., VASQUEZ, H. G., RUPAIMOOLE, R., PRADEEP, S., WU, S., ZAND, B., HAN, H.-D., RODRIGUEZ-AGUAYO, C., BOTTSFORD-MILLER, J. \& HUANG, J. 2014. Autocrine effects of tumor-derived complement. Cell reports, 6, 1085-1095.

CHOUDHURI, R., ZHANG, H.-T., DONNINI, S., ZICHE, M. \& BICKNELL, R. 1997. An angiogenic role for the neurokines midkine and pleiotrophin in tumorigenesis. Cancer research, 57, 1814-1819.

DAWSON, A., FERNANDEZ, M. L., ANGLESIO, M., YONG, P. J. \& CAREY, M. S. 2018. Endometriosis and endometriosis-associated cancers: new insights into the molecular mechanisms of ovarian cancer development. Ecancermedicalscience, 12.

DE LA CUESTA, R. S., EICHHORN, J. H., RICE, L. W., FULLER JR, A. F., NIKRUI, N. \& GOFF, B. A. 1996. Histologic transformation of benign endometriosis to early epithelial ovarian cancer. Gynecologic oncology, 60, 238-244.

DHILLON, A. S., HAGAN, S., RATH, O. \& KOLCH, W. 2007. MAP kinase signalling pathways in cancer. Oncogene, 26, 3279-3290.

DUCÈS, A., KARAKY, R., MARTEL-RENOIR, D., MIR, L., HAMMA-KOURBALI, Y., BIÉCHE, I., OPOLON, P., DELBE, J., COURTY, J. \& PERRICAUDET, M. 2008. 16-kDa fragment of pleiotrophin acts on 
endothelial and breast tumor cells and inhibits tumor development. Molecular cancer therapeutics, 7, 2817-2827.

ESQUIVEL-VELÁZQUEZ, M., OSTOA-SALOMA, P., PALACIOS-ARREOLA, M. I., NAVA-CASTRO, K. E., CASTRO, J. I., MORALES-MONTOR, J. \& RESEARCH, C. 2015. The role of cytokines in breast cancer development and progression. Journal of Interferon, 35, 1-16.

EYSTER, K. M., KLINKOVA, O., KENNEDY, V. \& HANSEN, K. A. 2007. Whole genome deoxyribonucleic acid microarray analysis of gene expression in ectopic versus eutopic endometrium. Fertility and sterility, 88, 1505-1533.

FLEMING, J.-A. G., SONG, G., CHOI, Y., SPENCER, T. E. \& BAZER, F. W. 2009. Interferon regulatory factor 6 (IRF6) is expressed in the ovine uterus and functions as a transcriptional activator. Molecular and cellular endocrinology, 299, 252-260.

GANDINI, S., LAZZERONI, M., PECCATORI, F., BENDINELLI, B., SAIEVA, C., PALLI, D., MASALA, G. \& CAINI, S. 2019. The risk of extra-ovarian malignancies among women with endometriosis: A systematic literature review and meta-analysis. Critical reviews in oncology/hematology, $134,72-81$.

GAVALAS, N., LIONTOS, M., TRACHANA, S.-P., BAGRATUNI, T., ARAPINIS, C., LIACOS, C., DIMOPOULOS, M. \& BAMIAS, A. 2013. Angiogenesis-related pathways in the pathogenesis of ovarian cancer. International journal of molecular sciences, 14, 15885-15909.

GIUDICE, L. C. \& KAO, L. C. 2004. Endometriosis. The Lancet, 364, 1789-1799.

HASHIGUCHI, M., KAI, K., NISHIYAMA, S., NAKAO, Y., YOKOYAMA, M. \& AISHIMA, S. 2018. Clear Cell Carcinoma of the Uterine Cervix Presented as a Submucosal Tumor Arising in a Background of Cervical Endometriosis. International Journal of Gynecological Pathology, 37, 88-92.

HAWKINS, S. M., CREIGHTON, C. J., HAN, D. Y., ZARIFF, A., ANDERSON, M. L., GUNARATNE, P. H. \& MATZUK, M. M. 2011. Functional microRNA involved in endometriosis. Molecular endocrinology, 25, 821-832.

HEIDEMANN, L. N., HARTWELL, D., HEIDEMANN, C. H. \& JOCHUMSEN, K. M. 2014. The relation between endometriosis and ovarian cancer-a review. Acta obstetricia et gynecologica Scandinavica, 93, 20-31.

HEIKKILÄ, K., EBRAHIM, S. \& LAWLOR, D. A. 2008. Systematic review of the association between circulating interleukin-6 (IL-6) and cancer. European Journal of Cancer, 44, 937-945.

HO, S.-M. 2003. Estrogen, progesterone and epithelial ovarian cancer. Reproductive Biology and Endocrinology, 1, 73.

HULKA, B. S. 1997. Epidemiologic analysis of breast and gynecologic cancers. Progress in clinical biologocal research, 396, 17-29.

IMAJO, M., TSUCHIYA, Y. \& NISHIDA, E. J. I. L. 2006. Regulatory mechanisms and functions of MAP kinase signaling pathways. IUMB Life, 58, 312-317.

JIMBO, H., YOSHIKAWA, H., ONDA, T., YASUGI, T., SAKAMOTO, A. \& TAKETANI, Y. 1997. Prevalence of ovarian endometriosis in epithelial ovarian cancer. International Journal of Gynecology \& Obstetrics, 59, 245-250.

KIM, E. K. \& CHOI, E.-J. 2010. Pathological roles of MAPK signaling pathways in human diseases. Biochimica et Biophysica Acta (BBA)-Molecular Basis of Disease, 1802, 396-405.

KIM, H., KIM, T., CHUNG, H. \& SONG, Y. 2014. Risk and prognosis of ovarian cancer in women with endometriosis: a meta-analysis. British journal of cancer, 110, 1878.

KOFF, J. L., RAMACHANDIRAN, S. \& BERNAL-MIZRACHI, L. 2015. A time to kill: targeting apoptosis in cancer. International journal of molecular sciences, 16, 2942-2955.

KOKCU, A. 2011. Relationship between endometriosis and cancer from current perspective. Archives of gynecology and obstetrics, 284, 1473-1479.

KONDI-PAFITI, A., SPANIDOU-CARVOUNI, H., PAPADIAS, K., HATZISTAMOU-KIARI, I., KONTOGIANNI, K., LIAPIS, A. \& SMYRNIOTIS, V. 2004. Malignant neoplasms arising in endometriosis: clinicopathological study of 14 cases. Clinical and experimental obstetrics \& gynecology, 31, 302-304. 
KVASKOFF, M., HORNE, A. W. \& MISSMER, S. A. 2017. Informing women with endometriosis about ovarian cancer risk. The Lancet, 390, 2433-2434.

KVASKOFF, M., MU, F., TERRY, K. L., HARRIS, H. R., POOLE, E. M., FARLAND, L. \& MISSMER, S. A. 2015. Endometriosis: a high-risk population for major chronic diseases? Human reproduction update, 21, 500-516.

LAVILLA-ALONSO, S., BAUER, M., ABO-RAMADAN, U., RISTIMÄKI, A., HALAVAARA, J., DESMOND, R., WANG, D., ESCUTENAIRE, S., AHTIAINEN, L. \& SAKSELA, K. 2012. Macrophage metalloelastase (MME) as adjuvant for intra-tumoral injection of oncolytic adenovirus and its influence on metastases development. Cancer gene therapy, 19, 126-134.

LIU, F., YANG, X., GENG, M. \& HUANG, M. J. A. P. S. B. 2018. Targeting ERK, an Achilles' Heel of the MAPK pathway, in cancer therapy. 8, 552-562.

MAEDA, D. \& SHIH, I.-M. 2013. Pathogenesis and the role of ARID1A mutation in endometriosisrelated ovarian neoplasms. Advances in anatomic pathology, 20, 45-52.

MAGLOTT, D., OSTELL, J., PRUITT, K. D. \& TATUSOVA, T. 2010. Entrez Gene: gene-centered information at NCBI. Nucleic Acids Research, 39, D52-D57.

MARWAH, N., GARG, M., SINGH, S., SETHI, D., SEN, R. J. I. J. O. A. \& RESEARCH, B. M. 2012. Unusual form of squamous cell carcinoma of the cervix extending in situ into the endometrium: Three case reports and review of literature. International Journal of Applied and Basic Medical Research, 2, 139-141.

MASAND, R. P., EUSCHER, E. D., DEAVERS, M. T. \& MALPICA, A. 2013. Endometrioid stromal sarcoma: a clinicopathologic study of 63 cases. The American journal of surgical pathology, 37, 1635-1647.

MELIN, A., SPAREN, P. \& BERGQVIST, A. 2007. The risk of cancer and the role of parity among women with endometriosis. Human reproduction, 22, 3021-3026.

MELIN, A., SPAREN, P., PERSSON, I. \& BERGQVIST, A. 2006. Endometriosis and the risk of cancer with special emphasis on ovarian cancer. Human reproduction, 21, 1237-1242.

MILDE-LANGOSCH, K., BAMBERGER, A., RIECK, G., GRUND, D., HEMMINGER, G., MÜLLER, V. \& LÖNING, T. J. B. J. O. C. 2005. Expression and prognostic relevance of activated extracellularregulated kinases (ERK1/2) in breast cancer. British journal of cancer, 92, 2206-2215.

MOGENSEN, J. B., KJAER, S. K., MELLEMKJ/ER, L. \& JENSEN, A. 2016. Endometriosis and risks for ovarian, endometrial and breast cancers: a nationwide cohort study. Gynecologic oncology, $143,87-92$.

MUNKSGAARD, P. S. \& BLAAKAER, J. 2011. The association between endometriosis and gynecological cancers and breast cancer: a review of epidemiological data. Gynecologic oncology, 123, 157-163.

MUROOKA, T. T., WARD, S. E. \& FISH, E. N. 2005. Chemokines and cancer. In: L.C., P. (ed.) Cytokines and Cancer. Boston, MA: Springer.

NABIZADEH, J. A., MANTHEY, H. D., STEYN, F. J., CHEN, W., WIDIAPRADJA, A., AKHIR, F. N. M., BOYLE, G. M., TAYLOR, S. M., WOODRUFF, T. M. \& ROLFE, B. 2016. The complement C3a receptor contributes to melanoma tumorigenesis by inhibiting neutrophil and CD4+ T cell responses. The journal of Immunology, 196, 4783-4792.

OPSTAL-VAN WINDEN, A. W., VERMEULEN, R. C., PEETERS, P. H., BEIJNEN, J. H., VAN GILS, C. H. J. B. C. R. \& TREATMENT 2012. Early diagnostic protein biomarkers for breast cancer: how far have we come? Breast Cancer Research and Treatment, 134, 1-12.

PAINTER, J. N., O'MARA, T. A., MORRIS, A. P., CHENG, T. H., GORMAN, M., MARTIN, L., HODSON, S., JONES, A., MARTIN, N. G. \& GORDON, S. 2018. Genetic overlap between endometriosis and endometrial cancer: evidence from cross-disease genetic correlation and GWAS metaanalyses. Cancer medicine, 7, 1978-1987.

PEARCE, C. L., TEMPLEMAN, C., ROSSING, M. A., LEE, A., NEAR, A. M., WEBB, P. M., NAGLE, C. M., DOHERTY, J. A., CUSHING-HAUGEN, K. L. \& WICKLUND, K. G. 2012. Association between 
631

632

633

634

635

636

637

638

639

640

641

642

643

644

645

646

647

648

649

650

651

652

653

654

655

656

657

658

659

660

661

662

663

664

665

endometriosis and risk of histological subtypes of ovarian cancer: a pooled analysis of casecontrol studies. The lancet oncology, 13, 385-394.

PIKE, M. C., GERKINS, V. R., CASAGRANDE, J. T., GRAY, G. E., BROWN, J. \& HENDERSON, B. E. J. N. C. I. M. 1979. The hormonal basis of breast cancer. ational Cancer Institute monograph, 187-193. RAUVALA, H. J. T. E. J. 1989. An 18-kd heparin-binding protein of developing brain that is distinct from fibroblast growth factors. he EMBO Journal 8, 2933-2941.

RENEHAN, A. G., SOERJOMATARAM, I. \& LEITZMANN, M. F. J. E. J. O. C. 2010. Interpreting the epidemiological evidence linking obesity and cancer: a framework for populationattributable risk estimations in Europe. European Journal of Cancer, 46, 2581-2592.

ROBINSON, M. J. \& COBB, M. H. 1997. Mitogen-activated protein kinase pathways. Current opinion in cell biology, 9, 180-186.

ROWLANDS, I. J., NAGLE, C. M., SPURDLE, A. B., WEBB, P. M., GROUP, A. N. E. C. S. \& GROUP, A. O. C. S. 2011. Gynecological conditions and the risk of endometrial cancer. Gynecologic oncology, 123, 537-541.

SAAVALAINEN, L., LASSUS, H., BUT, A., TIITINEN, A., HÄRKKI, P., GISSLER, M., PUKKALA, E. \& HEIKINHEIMO, O. 2018. Risk of Gynecologic Cancer According to the Type of Endometriosis. Obstetrics \& Gynecology, 131, 1095-1102.

SAAVALAINEN, L., LASSUS, H., BUT, A., TIITINEN, A., HÄRKKI, P., GISSLER, M., PUKKALA, E. \& HEIKINHEIMO, O. 2019. A cohort study of 49933 women with surgically verified endometriosis: Increased incidence of breast cancer below the age of 40. Acta obstetricia et gynecologica Scandinavica, 1-7.

SAMARTZIS, E. P., NOSKE, A., DEDES, K. J., FINK, D. \& IMESCH, P. 2013. ARID1A mutations and $\mathrm{PI} 3 \mathrm{~K} / \mathrm{AKT}$ pathway alterations in endometriosis and endometriosis-associated ovarian carcinomas. International journal of molecular sciences, 14, 18824-18849.

SAMPSON, J. A. 1927. Metastatic or embolic endometriosis, due to the menstrual dissemination of endometrial tissue into the venous circulation. The American journal of pathology, 3, 93-110.

SAWYERS, C. L. 2003. Opportunities and challenges in the development of kinase inhibitor therapy for cancer. Genes \& development, 17, 2998-3010.

SHANNON, P., MARKIEL, A., OZIER, O., BALIGA, N. S., WANG, J. T., RAMAGE, D., AMIN, N., SCHWIKOWSKI, B. \& IDEKER, T. 2003. Cytoscape: a software environment for integrated models of biomolecular interaction networks. Genome research, 13, 2498-2504.

SHUBIK, P. 1982. Vascularization of tumors: a review. Journal of cancer research clinical oncology, 103, 211-226.

STAMP, J. P., GILKS, C. B., WESSELING, M., ESHRAGH, S., CEBALLOS, K., ANGLESIO, M. S., KWON, J. S., TONE, A., HUNTSMAN, D. G. \& CAREY, M. S. 2016. BAF250a Expression in Atypical Endometriosis and Endometriosis-Associated Ovarian Cancer. International Journal of Gynecological Cancer, 26, 825-832.

SUBRAMANI, R., NANDY, S. B., PEDROZA, D. A. \& LAKSHMANASWAMY, R. 2017. Role of growth hormone in breast cancer. Endocrinology, 158, 1543-1555.

SUPEK, F., BOŠNJAK, M., ŠKUNCA, N. \& ŠMUC, T. 2011. REVIGO summarizes and visualizes long lists of gene ontology terms. PloS one, 6, e21800.

THOMAS, E. J. \& CAMPBELL, I. 2000. Evidence that endometriosis behaves in a malignant manner. Gynecologic and obstetric investigation, 50, 2-10.

TOMCZAK, K., CZERWIŃSKA, P. \& WIZNEROWICZ, M. 2015. The Cancer Genome Atlas (TCGA): an immeasurable source of knowledge. Contemporary oncology, 19, A68.

TOWNER, L. D., WHEAT, R. A., HUGHES, T. R. \& MORGAN, B. P. 2016. Complement Membrane Attack and Tumorigenesis A SYSTEMS BIOLOGY APPROACH. Journal of Biological Chemistry, 291, 14927-14938.

UIMARI, O., JÄRVELÄ, I. \& RYYNÄNEN, M. 2011. Do symptomatic endometriosis and uterine fibroids appear together? Journal of human reproductive sciences, 4, 34-38. 
VENN, A., WATSON, L., BRUINSMA, F., GILES, G. \& HEALY, D. 1999. Risk of cancer after use of fertility drugs with in-vitro fertilisation. The Lancet, 354, 1586-1590.

VERCELLINI, P., VIGANÒ, P., SOMIGLIANA, E. \& FEDELE, L. 2014. Endometriosis: pathogenesis and treatment. Nature Reviews Endocrinology, 10, 261-265.

WARDE-FARLEY, D., DONALDSON, S., COMES, O., ZUBERI, K., BADRAWI, R., CHAO, P., FRANZ, M., GROUIOS, C., KAZI, F., TANNUS LOPES, C., MAITLAND, A., MOSTAFAVI, S., MONTOJO, J., SHAO, Q., WRIGHT, G., D BADER, G. \& MORRIS, Q. 2010. The GeneMANIA prediction server: Biological network integration for gene prioritization and predicting gene function.

WEE, Y., WANG, T., LIU, Y., LI, X. \& ZHAO, M. 2018. A pan-cancer study of copy number gain and upregulation in human oncogenes. Life sciences, 211, 206-214.

WEI, J.-J., WILLIAM, J. \& BULUN, S. 2011. Endometriosis and ovarian cancer: a review of clinical, pathologic, and molecular aspects. International journal of gynecological pathology: official journal of the International Society of Gynecological Pathologists, 30, 553.

WETENDORF, M. \& DEMAYO, F. J. 2012. The progesterone receptor regulates implantation, decidualization, and glandular development via a complex paracrine signaling network. Molecular and cellular endocrinology, 357, 108-118.

WIEGAND, K. C., SHAH, S. P., AL-AGHA, O. M., ZHAO, Y., TSE, K., ZENG, T., SENZ, J., MCCONECHY, M. K., ANGLESIO, M. S. \& KALLOGER, S. E. 2010. ARID1A mutations in endometriosis-associated ovarian carcinomas. New England Journal of Medicine, 363, 1532-1543.

YAMADA, Y., TAKAYAMA, K. I., FUJIMURA, T., ASHIKARI, D., OBINATA, D., TAKAHASHI, S., IKEDA, K., KAKUTANI, S., URANO, T. \& FUKUHARA, H. 2017. A novel prognostic factor TRIM44 promotes cell proliferation and migration, and inhibits apoptosis in testicular germ cell tumor. Cancer science, 108, 32-41.

YANG, C., OH, H. K. \& KIM, D. 2014. Müllerian adenosarcoma arising from rectal endometriosis. Annals of coloproctology, 30, 232-236.

ZHANG, Y., BAO, W., WANG, K., LU, W., WANG, H., TONG, H. \& WAN, X. 2016. SOX17 is a tumor suppressor in endometrial cancer. Oncotarget, 7, 76036.

ZUCCHETTO, A., SERRAINO, D., POLESEL, J., NEGRI, E., DE PAOLI, A., DAL MASO, L., MONTELLA, M., LA VECCHIA, C., FRANCESCHI, S. \& TALAMINI, R. 2009. Hormone-related factors and gynecological conditions in relation to endometrial cancer risk. European journal of cancer prevention, 18, 316-321. 